đã quá đầy, điều đó có thể giúp chúng ta dễ dàng ngừng ăn trước khi ăn quá nhiều". Theo kết quả nghiên cứu của Dhananjai $S$, Sadashiiv và cộng sự (2013) về hiêu quả của tập Yoga ở bênh nhân béo phì cho thây tập Yoga có tác dụng làm giảm lo lắng, giảm trầm cảm và giảm cân nặng ở bệnh nhân béo phì [4].

Kết quả nghiên cứu của chúng tôi ở bảng 2 cho thấy; ở nhóm tập Yoga cải thiện có ý nghĩa các chỉ số nhân trắc liên qua đến tình trạng béo phì thừa cân là chỉ số BMI, số đo vòng bụng và bề dày lớp mõ dưới da bụng đều giảm có ý nghĩa thống kê sau thời điểm 3 tháng tập Yoga $(p<0,05)$. Kết quả nghiên cứu ở biểu đồ 1 và 2 cũng cho thấy; tập Yoga có tác dụng làm giảm có ý nghĩa thống kê tỷ lệ người tăng huyết áp độ 1 có thừa cân và béo bụng so với nhóm chứng. Ở nhóm tập Yoga, tại thời điểm bắt đầu nghiên cứu tỷ lê người bị thừa cân là $63,3 \%$ và sau thời gian tập Yoga tỷ lệ này giảm xuống còn $30 \%$. Tương tự, tập Yoga có tác dụng làm giảm có ý nghĩa tỷ lệ bệnh nhân béo bụng. Tại thời điểm bắt đầu nghiên cứu tỷ lệ bệnh nhân có béo bụng ở nhóm tập Yoga là $43,3 \%$ và sau thời gian tập Yoga tỷ lệ này giảm xuống còn $20 \%$ khác biệt có ý nghĩa thống kê so với nhóm chứng (biểu đồ 2).

\section{KẾT LUÂ̂N}

- Tập Yoga làm giảm có ý nghĩa thống kê các chỉ số huyết áp tâm thu và huyết áp tâm trương ở bệnh nhân tăng huyết áp độ 1 .

- Tập Yoga cũng làm giảm có ý nghĩa thống kê chỉ số BMI, vòng bụng và bề dày lớp mõ dưới da ở bệnh nhân tăng huyết áp độ 1 .

\section{TÀI LIÊU THAM KHẢO}

1. Phạm Thị Hằng $\mathrm{Nga}$, Hoàng Thị Ái Khuê (2011), Tác dụng của tập Yoga lên một số chỉ tiêu hình thái, sinh lý, sinh hóa ở bệnh nhân đái tháo đường tại thành phố Vinh, Luận văn thạc sỹ sinh họ.

2. Bhavanani $A B$, Madanmohan, and $Z$, Sanjay (2014), "Immediate cardiovascular effects of pranava pranayama in hypertensive patients", Indian J Physiol Parmacol. 12, pp. 125-129.

3. Caffrey $R, P$, Ruknui, and U, Hatthakit (2005), "The effects of Yoga on hypertensive persons in Thailand", Holistic Nursing Practice. 19(4), pp. 173-180.

4. Dhananjai $S$, Sadashiv, and $S$, Tiwari (2013), "Reducing psychological distress and obesity through Yoga practice", Int J Yoga. 12, pp. 213-216.

5. Hagin $M, R$, State, and Selfe (2016), "Effectiveness of Yoga for hypertension: systematic review and meta-analysis", Evid Based Complement Alternat Med.

6. Khatri D, KC, Mathur, and S, Gahlot (2017), "Effects of yoga and mediatation on clinical and biochemical parameters of metabolic syndrome", Diabetes Resercher and Clinical Practice. 78(3), pp. 9-10.

7. Mizuno J and HL, Monterio (2015), "An assessment of sequence of Yoga excercise to patients with arterial hypertension", Jounal of bodywork and movement thẻapies. 17, pp. 35-41.

8. Rajbhoj, Pratibha Hemant, Shete, Sanjay Uddhav, and Verma, Anita (2015), "Effect of Yoga Module on Pro-Inflammatory and AntiInflammatory Cytokines in Industrial Workers of Lonavla: A Randomized Controlled Trial", J Clin Diagn Res. 9(2), pp. 1-5.

\title{
BIẾN ĐổI SÓNG ALPHA TRÊN ĐIỆN NÃO BỆNH NHÂN TÂM THẦN PHÂN LIẸTT
}

\section{TÓM TẮT}

Mục tiêu: Tìm hiểu đặc điểm năng lượng, biên độ và tân số của sóng alpha trên điện não đố ở bệnh nhân tâm thần phân liệt. Phương pháp nghiên cứu: Phân tích về chỉ số năng lượng, tần số và biên độ của sóng alpha trên 100 bệnh nhẩn tâm thân phân liệt được điểu trị tại Khoa Tâm thân, Bệnh viện Quân y 103 và so sánh với ở 100 người trưởng thành khỏe mạnh. Kết quả nghiên cứu: Năng lượng và biên độ sóng alpha ở nhóm bệnh thấp hơn có ý nghĩa thống kê so với ở nhóm chứng ở hầu hết các kênh ghi ở hai

${ }^{1}$ Bệnh viện Quân y 103

Chịu trách nhiệm chính: Đinh Việt Hùng

Email: bshunga6@gmail.com

Ngày nhận bài: 23.2.2021

Ngày phản biên khoa học: 26.3.2021

Ngày duyệt bài: 5.4.2021
Đinh Việt Hùng1, Nguyễn Văn Linh ${ }^{1}$ giai đoạn nhắm mắt và giai đoạn tăng thông khí. Trong khi đó tần số sóng alpha khổng có sự biên đổi ở bệnh nhân tâm thần phân liệt so với nhóm chứng. Kết luận: Kết quả nghiên cứu này đưa ra bằng chứng về sự biến đổi sóng alpha trên điện não ở bệnh nhân tâm thần phân liệt.

Tư khóa: Tẩm thần phân liệt, năng lượng, biên độ, tần số, sóng alpha.

\section{SUMMARY}

\section{CHANGES OF ALPHA WAVES IN \\ ELECTROENCEPHALOGRAMS OF SCHIZOPHRENIA PATIENTS}

Objectives: Investigate the energy characteristics, amplitude and frequency of alpha waves from electroencephalography recordings in schizophrenia patients. Methods: Analysis of energy index, frequency and amplitude of alpha waves in 100 
schizophrenia patients treated at Department of Psychiatry, Military Hospital 103, which were then compared to those in 100 healthy subjects. Results: The energy and amplitude of alpha waves in the patient group was statistically significantly lower than in the control group in most of the channels recorded in the closed and hyperventilation phases. Meanwhile, the alpha wave frequency did not change in schizophrenia patients compared with the control group. Conclusions: The present study provided new evidence for changes of alpha waves in electroencephalography recordings from patients with schizophrenia.

Keywords: Schizophrenia, energy, amplitude frequency, alpha wave.

\section{I. ĐĂT VẤN ĐỀ}

Tâm thần phân liêt (TTPL) là môt nhóm bênh loạn thần nặng, với đặc trưng là các triệu chứng loạn thần như hoang tưởng, ảo giác, căng trương lực, hành vi thanh xuân và ngôn ngữ thanh xuân. Các triệu chứng của tâm thần phân liệt rất đa dạng, phong phú và chúng luôn thay đổi theo thời gian [1]. Tâm thần phân liệt chiếm khoảng $1 \%$ dân số, con số này là rất lớn vì ở nước ta có gần 1 triệu người bị tâm thần phân liệt. Số bệnh nhân này thực sự là một gánh nặng cho xã hội vì bệnh nhân sẽ mất dần khả nằng lao động [2]. Do đó, phát hiện và có các biện pháp can thiệp sớm là những giải pháp góp phần ngăn chặn tiến triển của bệnh. Hiện nay việc nghiên cứu và phân tích điện não đồ ở bệnh nhân TTPL có vai trò quan trọng. Việc ứng dụng phân tích và đánh giá điện não đồ bằng các phần mềm hiện còn mới mẻ ở Việt Nam. Bởi vậy, chúng tôi tiến hành nghiên cứu này nhằm: Phân tích sự biến đổi năng lượng, biên độ và tần số sóng alpha trên điện não đồ ở bệnh nhân TTPL.

II. ĐỐI TƯỢNG VÀ PHƯƠNG PHÁP NGHIÊN CỨU

2.1. Đối tượng nghiên cứu. Đối tượng nghiên cứu gồm 100 bệnh nhân đáp ứng đầy đủ tiêu chuẩn chẩn đoán TTPL theo ICD-10 điều trị nội trú tại Khoa Tâm thần-Bệnh viện Quân y 103 từ tháng $9 / 2018$ đến tháng $9 / 2020$. Nhóm chứng gồm 100 người khoẻ mạnh, bình thường phù hợp với nhóm bệnh nhân nghiên cứu về tuổi, giới tính và một số điêuu kiện khác, tự nguyện tham gia nghiên cứu này.

2.2. Phương pháp nghiên cứu. Sử dụng phương pháp nghiên cứu hồi cứu mô tả cắt ngang, phân tích đánh giá từng trường hợp cụ thể. Điện não bệnh nhân được ghi trong vòng 5 ngày đầu sau khi vào viện. Đối với người bình thường trước khi ghi điện não 3 ngày không dùng thuốc kích thích, an thần hoặc gây ngủ, không có tình trạng mất ngủ đêm hôm trước, mệt mỏi, đói. Các thông số định lượng điện não đồ thực hiện trên phần mềm EEGLab v13.4.4b chạy trên môi trường MatLab 2019.

2.3. Phân tích số liệu. Phân tích số liệu được tiến hành trên phần mềm phân tích số liệu SPSS 20.0. Sự khác biệt có ý nghĩa thống kê được xác định cho các kiểm định với mức $p<0,05$.

\section{KẾT QUẢ NGHIÊN CỨU}

3.1. Năng lượng sóng alpha

3.1.1. Năng lượng sóng alpha ở bán câu trái

Bảng 3.1. Năng lương sóng alpha ở bán cầu trái giai đoạn nhắm mắt

\begin{tabular}{|c|c|c|c|}
\hline $\begin{array}{l}\text { Chì số thống kê } \\
\text { Diện cực }\end{array}$ & $\begin{array}{l}\text { Nhóm } \\
\text { bệnh }\end{array}$ & $\begin{array}{l}\text { Nhóm } \\
\text { chứng }\end{array}$ & $\mathbf{p}$ \\
\hline $\mathrm{C} 3$ & $\begin{array}{r}37,87 \\
\pm 7,61 \\
\end{array}$ & $\begin{array}{c}37,00 \pm \\
10,82\end{array}$ & 0,527 \\
\hline F3 & $\begin{array}{r}42,31 \\
\pm 7,59\end{array}$ & $\begin{array}{c}50,87 \pm \\
15,44\end{array}$ & \multirow{5}{*}{$<0,05$} \\
\hline Fp1 & $\begin{array}{c}49,50 \\
\pm 10,02 \\
\end{array}$ & $\begin{array}{c}59,52 \pm \\
20,14 \\
\end{array}$ & \\
\hline 01 & $\begin{array}{c}70,07 \\
\pm 15,62 \\
\end{array}$ & $\begin{array}{c}85,12 \pm \\
24,81 \\
\end{array}$ & \\
\hline P3 & $\begin{array}{c}52,36 \\
\pm 11,48\end{array}$ & $\begin{array}{c}69,56 \pm \\
24,84\end{array}$ & \\
\hline T3 & $\begin{array}{r}50,08 \\
\pm 9,38\end{array}$ & $\begin{array}{c}60,92 \pm \\
26,57\end{array}$ & \\
\hline
\end{tabular}

Bảng 3.1 thể hiện năng lượng sóng alpha ơ bán cầu trái giai đoạn nhắm mắt giữa hai nhóm nghiên cứu. Năng lượng sóng alpha ở nhóm bệnh thấp hơn có ý nghĩa thống kê so với ở nhóm chứng ở bán cầu trái trừ điện cực trung tâm. Trong đó năng lượng sóng alpha ở bệnh nhân tâm thần phân liệt thể hiện thấp nhất so với nhóm chứng ở vùng đỉnh trái.

Bảng 3.2. Năng lượng sóng alpha ở bán cầu trái giai đoạn tăng thông khí

\begin{tabular}{|c|c|c|c|}
\hline $\begin{array}{l}\text { Chì số thống kê } \\
\text { Diện cực }\end{array}$ & $\begin{array}{l}\text { Nhóm } \\
\text { bệnh }\end{array}$ & $\begin{array}{l}\text { Nhóm } \\
\text { chứng }\end{array}$ & $\mathbf{p}$ \\
\hline C3 & $\begin{array}{r}38,29 \\
\pm 8,57 \\
\end{array}$ & $\begin{array}{c}37,54 \pm \\
11,38\end{array}$ & 0,604 \\
\hline F3 & $\begin{array}{r}43,74 \\
\pm 9,78\end{array}$ & $\begin{array}{c}52,13 \pm \\
14,14\end{array}$ & \multirow{5}{*}{$<0,05$} \\
\hline Fp1 & $\begin{array}{r}50,66 \\
\pm 12,10 \\
\end{array}$ & $\begin{array}{c}61,97 \pm \\
18,94\end{array}$ & \\
\hline O1 & $\begin{array}{r}71,29 \\
\pm 16,92\end{array}$ & $\begin{array}{l}86,66 \pm \\
25,26\end{array}$ & \\
\hline P3 & $\begin{array}{c}53,91 \\
\pm 12,17\end{array}$ & $\begin{array}{c}71,27 \pm \\
27,54\end{array}$ & \\
\hline T3 & $\begin{array}{r}51,80 \\
\pm 10,53\end{array}$ & $\begin{array}{c}60,15 \pm \\
15,03\end{array}$ & \\
\hline
\end{tabular}

Bảng 3.2 thể hiện năng lượng sóng alpha ơ bán cầu trái giai đoạn tăng thông khí giữa hai nhóm nghiên cứu. Năng lượng sóng alpha ở nhóm bệnh cũng thấp hơn có ý nghĩa thống kê 
so với ở nhóm chứng ở bán cầu trái trừ điện cực trung tâm. Trong đó năng lượng sóng alpha ở bệnh nhân tâm thần phân liệt thể hiện thấp nhất so với nhóm chứng ở vùng đỉnh trái $(53,91 \pm$ $12,17 \mu \mathrm{V}^{2} / \mathrm{Hz}$ so $71,27 \pm 27,54 \mu \mathrm{V}^{2} / \mathrm{Hz}$ ).

3.1.2. Năng lượng sóng alpha ở bán câu phải

Bảng 3.3. Năng lương sóng alpha ở bán cầu phải giai đoạn nhắm măt

\begin{tabular}{|c|c|c|c|}
\hline $\begin{array}{l}\text { Chỉsố thống kê } \\
\text { Điện cực }\end{array}$ & $\begin{array}{l}\text { Nhóm } \\
\text { bệnh }\end{array}$ & $\begin{array}{l}\text { Nhóm } \\
\text { chứng }\end{array}$ & $\mathbf{p}$ \\
\hline C4 & $\begin{array}{c}37,85 \pm \\
7,65\end{array}$ & $\begin{array}{c}36,85 \pm \\
10,91\end{array}$ & 0,468 \\
\hline F4 & $\begin{array}{l}44,13 \pm \\
12,72\end{array}$ & $\begin{array}{c}52,57 \pm \\
16,58\end{array}$ & \multirow{5}{*}{$<0,05$} \\
\hline Fp2 & $\begin{array}{c}49,10 \pm \\
10,27\end{array}$ & $\begin{array}{c}57,59 \pm \\
16,58\end{array}$ & \\
\hline $\mathrm{O} 2$ & $\begin{array}{c}72,02 \pm \\
15,84\end{array}$ & $\begin{array}{l}85,72 \pm \\
25,61\end{array}$ & \\
\hline P4 & $\begin{array}{c}53,33 \pm \\
10,91\end{array}$ & $\begin{array}{c}69,20 \pm \\
21,34\end{array}$ & \\
\hline T4 & $\begin{array}{c}50,65 \pm \\
10,31\end{array}$ & $\begin{array}{c}59,84 \pm \\
13,80\end{array}$ & \\
\hline
\end{tabular}

Kết quả Bảng 3.3 chỉ ra rằng năng lượng sóng alpha ở bán cầu phải giai đoạn nhắm mắt giữa hai nhóm nghiên cứu. Năng lượng sóng alpha ở nhóm bệnh thấp hơn có ý nghĩa thống kê so với ở nhóm chứng ở bán cầu phải trừ điện cực trung tâm. Trong đó năng lượng sóng alpha ở bệnh nhân tâm thần phân liệt thể hiện thấp nhất ở vùng trung tâm và vùng trán $(37,85 \pm$ $7,65 \mu \mathrm{V}^{2} / \mathrm{Hz}$ và $\left.44,13 \pm 12,72 \mu \mathrm{V}^{2} / \mathrm{Hz}\right)$.

Bảng 3.4. Năng lượng sóng alpha ở bán cầu phải giai đoạn tăng thồng khí

\begin{tabular}{|c|c|c|c|}
\hline $\begin{array}{l}\text { Chỉ số thống kê } \\
\text { Diện cực }\end{array}$ & $\begin{array}{l}\text { Nhóm } \\
\text { bệnh }\end{array}$ & $\begin{array}{l}\text { Nhóm } \\
\text { chứng }\end{array}$ & $\mathbf{p}$ \\
\hline C4 & $\begin{array}{c}38,30 \pm \\
8,35\end{array}$ & $\begin{array}{c}37,51 \pm \\
11,23\end{array}$ & 0,604 \\
\hline $\mathrm{F} 4$ & $\begin{array}{c}43,21 \pm \\
10,19\end{array}$ & $\begin{array}{c}52,65 \pm \\
16,23\end{array}$ & \\
\hline Fp2 & $\begin{array}{c}51,27 \pm \\
20,30\end{array}$ & $\begin{array}{c}60,31 \pm \\
15,75\end{array}$ & \\
\hline $\mathrm{O} 2$ & $\begin{array}{c}72,86 \pm \\
16,60\end{array}$ & $\begin{array}{c}86,79 \pm \\
24,42\end{array}$ & $<0,05$ \\
\hline P4 & $\begin{array}{c}54,14 \pm \\
11,38\end{array}$ & $\begin{array}{c}70,43 \pm \\
22,92\end{array}$ & \\
\hline T4 & $\begin{array}{c}52,08 \pm \\
11,54\end{array}$ & $\begin{array}{c}60,94 \pm \\
17,66\end{array}$ & \\
\hline
\end{tabular}

Kết quả Bảng 3.3 chỉ ra rằng năng lượng sóng alpha ở bán cầu phải giai đoạn tăng thồng khí ở nhóm bệnh thấp hơn có ý nghĩa thống kê so với ở nhóm chứng ở bán câu phải trừ điện cực trung tâm. Trong đó năng lượng sóng alpha ở bệnh nhân tâm thần phân liệt thể hiện cao nhất ở vùng chẩm $\left(72,86 \pm 16,60 \mu \mathrm{V}^{2} / \mathrm{Hz}\right)$.

\subsection{Biên độ sóng alpha}

3.2.1. Biên độ sóng alpha ở bán câu trái

Bảng 3.5. Biển độ sóng alpha ở bán cầu trái giai đoạn nhắm măt

\begin{tabular}{|c|c|c|c|}
\hline $\begin{array}{l}\text { Chì số thống kê } \\
\text { biện cực }\end{array}$ & $\begin{array}{l}\text { Nhóm } \\
\text { bệnh }\end{array}$ & $\begin{array}{l}\text { Nhóm } \\
\text { chứng }\end{array}$ & p \\
\hline C3 & $\begin{array}{c}7,98 \pm \\
3,26\end{array}$ & $\begin{array}{c}8,69 \pm \\
5,17\end{array}$ & 0,264 \\
\hline F3 & $\begin{array}{c}9,78 \pm \\
4,00\end{array}$ & $\begin{array}{c}15,24 \pm \\
9,08\end{array}$ & \multirow{5}{*}{$<0,05$} \\
\hline Fp1 & $\begin{array}{r}12,98 \\
\pm 5,79 \\
\end{array}$ & $\begin{array}{c}21,23 \pm \\
18,09\end{array}$ & \\
\hline 01 & $\begin{array}{r}29,39 \\
\pm 13,31 \\
\end{array}$ & $\begin{array}{c}44,26 \pm \\
26,19\end{array}$ & \\
\hline P3 & $\begin{array}{r}16,40 \\
\pm 7,41\end{array}$ & $\begin{array}{c}32,51 \pm \\
23,50\end{array}$ & \\
\hline T3 & $\begin{array}{r}13,56 \\
\pm 5,72\end{array}$ & $\begin{array}{c}24,99 \pm \\
41,82\end{array}$ & \\
\hline
\end{tabular}

Bảng 3.5 chỉ ra rằng biên độ sóng alpha ờ bán cầu trái giai đoạn nhắm mắt ở nhóm bệnh không đồng đều giữa các vùng và thấp hơn có ý nghĩa thống kê so với ở nhóm chứng ở bán cầu phải trừ điện cực trung tâm. Trong đó biên độ sóng alpha thấp nhất và cao nhất ở bệnh nhân tâm thần phân liệt ở vùng trung tâm và chẩm $(7,98 \pm 3,26 \mu \mathrm{V}$ và $29,39 \pm 13,31 \mu \mathrm{V})$.

Bảng 3.6. Biên độ sóng alpha ở bán cầu trái giai đoạn tăng thông khí

\begin{tabular}{|c|c|c|c|}
\hline $\begin{array}{l}\text { Chỉ số thống kế } \\
\text { Diện cực }\end{array}$ & $\begin{array}{l}\text { Nhóm } \\
\text { bệnh }\end{array}$ & $\begin{array}{l}\text { Nhóm } \\
\text { chứng }\end{array}$ & $\mathbf{p}$ \\
\hline C3 & $\begin{array}{c}8,42 \pm \\
3,61\end{array}$ & $\begin{array}{c}9,47 \pm \\
6,47\end{array}$ & 0,168 \\
\hline F3 & $\begin{array}{c}10,02 \pm \\
4,45\end{array}$ & $\begin{array}{c}17,09 \pm \\
10,77\end{array}$ & \multirow{5}{*}{$<0,05$} \\
\hline Fp1 & $\begin{array}{c}13,04 \pm \\
5,65\end{array}$ & $\begin{array}{c}23,02 \pm \\
14,01\end{array}$ & \\
\hline 01 & $\begin{array}{c}30,55 \pm \\
13,90\end{array}$ & $\begin{array}{c}45,88 \pm \\
27,76\end{array}$ & \\
\hline P3 & $\begin{array}{c}16,77 \pm \\
7,36\end{array}$ & $\begin{array}{c}34,17 \pm \\
26,58\end{array}$ & \\
\hline T3 & $\begin{array}{c}14,17 \pm \\
6,14\end{array}$ & $\begin{array}{c}22,08 \pm \\
11,66\end{array}$ & \\
\hline
\end{tabular}

Ở giai đoạn tăng thông khí biên độ sóng alpha ở bán cầu trái cũng có sự tương đồng như ở giai đoạn nhắm mắt. Biên độ sóng alpha ở bệnh nhân tâm thần phân liệt thấp hơn so với nhóm chúng ở các vùng trán, vùng trán trước, vùng chẩm, vùng đỉnh và vùng thái dương.

3.2.2. Biên độ sóng alpha ở bán câu phải

Bảng 3.7. Biền độ sóng alpha ở bán cầu phải giai đoạn nhắm mắt

\begin{tabular}{|c|c|c|c|}
\hline $\begin{array}{c}\text { Chì số thống kêe } \\
\text { Diện cực }\end{array}$ & $\begin{array}{c}\text { Nhóm } \\
\text { bệnh }\end{array}$ & $\begin{array}{c}\text { Nhóm } \\
\text { chứng }\end{array}$ & $\mathbf{p}$ \\
\hline $\mathrm{C} 4$ & $8,03 \pm$ & $8,68 \pm$ & 0,309 \\
\hline
\end{tabular}


VIETNAM MEDICAL JOURNAL N²2 - APRIL - 2021

\begin{tabular}{|c|c|c|}
\hline F4 & $\begin{array}{c}11,03 \pm \\
9,33\end{array}$ & $\begin{array}{c}16,36 \\
\pm 10,06\end{array}$ \\
\hline Fp2 & $\begin{array}{c}13,29 \pm \\
9,61\end{array}$ & $\begin{array}{c}19,37 \\
\pm 9,93\end{array}$ \\
\hline O2 & $\begin{array}{c}31,38 \pm \\
14,30\end{array}$ & $\begin{array}{c}48,43 \\
\pm 27,63\end{array}$ \\
\hline P4 & $\begin{array}{c}16,88 \pm \\
7,19\end{array}$ & $\begin{array}{c}31,31 \\
\pm 19,38\end{array}$ \\
\hline T4 & $13,26 \pm$ & 20,92 \\
& 5,50 & $\pm 9,71$ \\
\hline
\end{tabular}

Bán câu phải ở giai đoạn nhắm mắt thì biên độ sóng alpha ở bệnh nhân thấp hơn biên độ sóng alpha của nhóm chứng. Cụ thể biên độ sóng alpha ở bệnh nhân dao động từ 8,03 \pm 3,26 $\mu \mathrm{V}$ ở vùng trung tâm đến $31,38 \pm 14,30 \mu \mathrm{V}$ ở vùng chẩm. Trong khi đó biên độ sóng alpha ở nhóm chứng có sự dao động lớn hơn từ 8,68 \pm $5,19 \mu \mathrm{V}$ ở vùng trung tâm đến $48,43 \pm 27,63 \mu \mathrm{V}$ ở vùng chẩm.

Bảng 3.8. Biên độ sóng alpha ở bán cầu phải giai đoạn tăng thông khí

\begin{tabular}{|c|c|c|c|}
\hline $\begin{array}{l}\text { Chísố thống kề } \\
\text { Diện cực }\end{array}$ & $\begin{array}{l}\text { Nhóm } \\
\text { bệnh }\end{array}$ & $\begin{array}{l}\text { Nhóm } \\
\text { chứng }\end{array}$ & $\mathbf{p}$ \\
\hline C4 & $\begin{array}{l}8,43 \pm \\
3,59\end{array}$ & $\begin{array}{c}9,43 \pm \\
6,28\end{array}$ & 0.176 \\
\hline F4 & $\begin{array}{c}10,06 \pm \\
6,43\end{array}$ & $\begin{array}{r}17,92 \\
\pm 9,37\end{array}$ & \multirow{5}{*}{$<0,05$} \\
\hline Fp2 & $\begin{array}{c}16,38 \pm \\
12,48\end{array}$ & $\begin{array}{r}22,11 \\
\pm 11,93\end{array}$ & \\
\hline $\mathrm{O} 2$ & $\begin{array}{c}31,98 \pm \\
14,15\end{array}$ & $\begin{array}{r}48,58 \\
\pm 25,69\end{array}$ & \\
\hline P4 & $\begin{array}{c}16,90 \pm \\
6,78\end{array}$ & $\begin{array}{r}33,16 \\
\pm 23,20\end{array}$ & \\
\hline T4 & $\begin{array}{c}14,32 \pm \\
5,83\end{array}$ & $\begin{array}{r}22,83 \\
\pm 14,93\end{array}$ & \\
\hline
\end{tabular}

Bảng 3.8 thể hiện biên độ sóng alpha ở bệnh nhân thấp hơn biển độ sóng alpha của nhóm chứng ở giai đoạn tăng thông khí. Biên độ sóng alpha ở bệnh nhân có sự ổn định ở vùng trán trước, vùng đỉnh và vùng thái dương $(16,38 \pm$ $12,48 \mu \mathrm{V} ; \quad 16,90 \pm 6,78 \mu \mathrm{V}$ và $14,32 \pm 5,83 \mu \mathrm{V})$. Còn biên độ sóng alpha ở nhóm chứng có sự ôn định ở vùng trán trước và vùng thái dương $(22,11 \pm 11,93 \mu \mathrm{V}$ và $22,83 \pm 14,93 \mu \mathrm{V})$.

\subsection{Tân số sóng alpha}

3.3.1. Tân số sóng alpha ở bán câu trái

Bảng 3.9. Tần số sóng alpha ở bán cầu trái giai đoạn nhắm mắt

\begin{tabular}{|c|c|c|c|}
\hline $\begin{array}{l}\text { Chỉ số thống kê } \\
\text { Điện cực }\end{array}$ & $\begin{array}{l}\text { Nhóm } \\
\text { bệnh }\end{array}$ & $\begin{array}{l}\text { Nhóm } \\
\text { chứng }\end{array}$ & $\mathbf{p}$ \\
\hline C3 & $\begin{array}{c}10,50 \pm \\
0,19\end{array}$ & $\begin{array}{r}10,50 \\
\pm 0,17\end{array}$ & \multirow{3}{*}{$\stackrel{>}{0,05}$} \\
\hline F3 & $\begin{array}{c}10,49 \pm \\
0,21\end{array}$ & $\begin{array}{r}10,51 \\
\pm 0,20\end{array}$ & \\
\hline Fp1 & $\begin{array}{c}10,50 \pm \\
0,21\end{array}$ & $\begin{array}{r}10,52 \\
\pm 0,15\end{array}$ & \\
\hline
\end{tabular}

\begin{tabular}{|c|c|c|}
\hline O1 & $\begin{array}{c}10,51 \pm \\
0,17\end{array}$ & $\begin{array}{c}10,51 \\
\pm 0,18\end{array}$ \\
\hline P3 & $10,47 \pm$ & 10,52 \\
0,21 & $\pm 0,17$ \\
\hline T3 & $10,52 \pm$ & 10,49 \\
& 0,17 & $\pm 0,19$ \\
\hline
\end{tabular}

Bảng 3.8 thể hiện tân số sóng alpha ở bệnh nhân không thay đổi so với tân số sóng alpha của nhóm chứng ở giai đoạn nhắm mắt. Tân số sóng alpha ở bệnh nhân và nhóm chứng đều có sự dao động nhỏ từ 10,47 \pm 0,21 ck/s tới 10,52 $\pm 0,17 \mathrm{ck} / \mathrm{s}$.

Bảng 3.10. Tần số sóng alpha ở bán cầu trái giai đoạn tăng thông khí

\begin{tabular}{|c|c|c|c|}
\hline $\begin{array}{l}\text { Chí số thống kê } \\
\text { Diện cực }\end{array}$ & $\begin{array}{l}\text { Nhóm } \\
\text { bệnh }\end{array}$ & $\begin{array}{l}\text { Nhóm } \\
\text { chứng }\end{array}$ & $\mathbf{p}$ \\
\hline C3 & $\begin{array}{c}10,52 \pm \\
0,20\end{array}$ & $\begin{array}{c}10,53 \pm \\
0,15\end{array}$ & \multirow{6}{*}{0,05} \\
\hline F3 & $\begin{array}{c}10,48 \pm \\
0,16\end{array}$ & $\begin{array}{c}10,47 \pm \\
0,16\end{array}$ & \\
\hline Fp1 & $\begin{array}{c}10,51 \pm \\
0,20\end{array}$ & $\begin{array}{c}10,45 \pm \\
0,17\end{array}$ & \\
\hline O1 & $\begin{array}{c}10,52 \pm \\
0,17\end{array}$ & $\begin{array}{c}10,49 \pm \\
0,18\end{array}$ & \\
\hline P3 & $\begin{array}{c}10,53 \pm \\
0,18\end{array}$ & $\begin{array}{c}10,54 \pm \\
0,16\end{array}$ & \\
\hline T3 & $\begin{array}{c}10,49 \pm \\
0,19\end{array}$ & $\begin{array}{c}10,49 \pm \\
0,18\end{array}$ & \\
\hline
\end{tabular}

Giai đoạn tăng thông khí tân số sóng alpha ở bệnh nhân ở bán câu trái không thay đổi so với tần số sóng alpha của nhóm chứng. Tân số sóng alpha ở bệnh nhân cao nhất ở vùng đỉnh và thấp ở vùng trán $10,53 \pm 0,18 \mathrm{ck} / \mathrm{s}$ và $10,48 \pm 0,16 \mathrm{ck} / \mathrm{s}$.

3.3.2. Tân số sóng alpha ở bán câu phải

Bảng 3.11. Tần số sóng alpha ở bán cầu phải giai đoạn nhắm mắt

\begin{tabular}{|c|c|c|c|}
\hline $\begin{array}{l}\text { Chi số thống kê } \\
\text { Điện cực }\end{array}$ & $\begin{array}{l}\text { Nhóm } \\
\text { bệnh }\end{array}$ & $\begin{array}{l}\text { Nhóm } \\
\text { chứng }\end{array}$ & p \\
\hline C4 & $\begin{array}{c}10,50 \pm \\
0,19\end{array}$ & $\begin{array}{c}10,45 \pm \\
0,17\end{array}$ & \multirow{6}{*}{0,05} \\
\hline F4 & $\begin{array}{c}10,50 \pm \\
0,19\end{array}$ & $\begin{array}{c}10,48 \pm \\
0,19\end{array}$ & \\
\hline Fp2 & $\begin{array}{c}10,53 \pm \\
0,18\end{array}$ & $\begin{array}{c}10,46 \pm \\
0,16\end{array}$ & \\
\hline $\mathrm{O} 2$ & $\begin{array}{c}10,50 \pm \\
0,16\end{array}$ & $\begin{array}{c}10,49 \pm \\
0,19\end{array}$ & \\
\hline P4 & $\begin{array}{c}10,52 \pm \\
0,17\end{array}$ & $\begin{array}{c}10,50 \pm \\
0,18\end{array}$ & \\
\hline T4 & $\begin{array}{c}10,49 \pm \\
0,18\end{array}$ & $\begin{array}{c}10,50 \pm \\
0,19\end{array}$ & \\
\hline
\end{tabular}

Bảng 3.11 chỉ ra rằng không có sự thay đổi tân số sóng alpha ở bán câu phải trong giai đoạn nhắm mắt giữa bệnh nhân tâm thân phân liệt và nhóm chứng. Tần số sóng alpha ở hai nhóm dao đồng từ 10,45 $\pm 0,17 \mathrm{ck} / \mathrm{s}$ đến $10,53 \pm 0,18 \mathrm{ck} / \mathrm{s}$.

Bảng 3.12. Tần số sóng alpha ở bán cầu 
phải giai đoạn tăng thông khí

\begin{tabular}{|c|c|c|c|}
\hline $\begin{array}{l}\text { Chì số thống kê } \\
\text { Điện cực }\end{array}$ & $\begin{array}{l}\text { Nhóm } \\
\text { bệnh }\end{array}$ & $\begin{array}{l}\text { Nhóm } \\
\text { chứng }\end{array}$ & $\mathbf{p}$ \\
\hline C4 & $\begin{array}{c}10,50 \pm \\
0,20\end{array}$ & $\begin{array}{c}10,52 \pm \\
0,15\end{array}$ & \multirow{6}{*}{$\stackrel{>}{0,05}$} \\
\hline $\mathrm{F} 4$ & $\begin{array}{c}10,50 \pm \\
0,17\end{array}$ & $\begin{array}{c}10,46 \pm \\
0,19\end{array}$ & \\
\hline Fp2 & $\begin{array}{c}10,54 \pm \\
0,16\end{array}$ & $\begin{array}{c}10,48 \pm \\
0,17\end{array}$ & \\
\hline $\mathrm{O} 2$ & $\begin{array}{c}10,51 \pm \\
0,18\end{array}$ & $\begin{array}{c}10,53 \pm \\
0,19\end{array}$ & \\
\hline P4 & $\begin{array}{c}10,50 \pm \\
0,19\end{array}$ & $\begin{array}{c}10,50 \pm \\
0,19\end{array}$ & \\
\hline T4 & $\begin{array}{c}10,49 \pm \\
0,18\end{array}$ & $\begin{array}{c}10,49 \pm \\
0,18\end{array}$ & \\
\hline
\end{tabular}

Kết quả Bảng 3.12 chỉ ra rằng không có sự thay đổi tần số sóng alpha ở bán cầu phải trong giai đoạn tăng thông khí giữa bệnh nhân tâm thần phân liệt và nhóm chứng. Tân số sóng alpha ở hai nhóm dao đồng từ 10,46 $\pm 0,19 \mathrm{ck} / \mathrm{s}$ đến $10,54 \pm 0,16 \mathrm{ck} / \mathrm{s}$.

\section{BÀN LUÂ̂N}

Chúng tôi nhận thấy năng lượng sóng alpha ở nhóm bệnh nhân thấp hơn so với nhóm chứng là những người khỏe mạnh ở cùng lứa tuổi với người bệnh. Đối với biến đổi điện não thì chỉ số năng lượng sóng được nhiều nhà nghiên cứu trên thế giới tập trung phân tích. Kết quả nghiên cứu của chúng tôi gợi ý rằng trên bệnh nhân TTPL hoạt động của sóng alpha giảm so với đối tượng là những người khỏe mạnh cho thấy sự mất cân bằng giữa hoạt động ức chế và hưng phấn trên vỏ não ở bệnh nhân TTPL. Kết quả này phù hợp với nghiên cứu của Moeini và CS. (2014) khi phân tích điện não ở 40 bệnh nhân TTPL và 40 người khỏe mạnh thì tác giả thấy năng lượng sóng alpha có xu hướng giảm ở bệnh nhần so với người khỏe mạnh ở tất cả các vùng trừ vùng trán và vùng thái dương [3]. Mặt khác chúng tôi thấy rằng năng lượng sóng alpha ở bệnh nhân giảm so với nhóm người khỏe mạnh ở giai đoạn tăng thông khí. Như vậy kết quả này tương đồng với nghiên cứu của Kim và CS. (2015) chỉ ra rằng năng lượng sóng alpha khác biệt đáng kể giữa các vùng ở giai đoạn tăng thông khí [4].

Biên độ của các sóng trên điện não đồ chúng tôi có nhận xét chung là biên độ sóng alpha ở bệnh nhân TTPL thấp hơn so với nhóm chứng là những người không mắc bệnh TTPL. Sự khác biệt này chủ yếu thấy ở vùng chẩm hai bển. Kết quả của chúng tôi phù hợp với những ghi nhận về sự thay đổi biên độ các sóng điện não đồ trền điện não đồ mà các tác giả trước đây đã công bố như tác giả Itoh và CS. (2011) khi so sánh điện não đồ giữa bệnh nhân TTPL và người khỏe mạnh, tác giả thây biên độ sóng alpha giảm đáng kể ở bệnh nhân với sự khác biệt tối đa được tìm thấy ở khu vực thái dương bên trái [5]. Tác giả Ranlund và CS. (2014) nhận thấy biên độ sóng alpha thấp nhất ở bệnh nhẩn TTPL mạn tính so với TTPL cấp tính và người khỏe mạnh. Còn nghiên cứu của Kirino (2004) cũng thấy biên độ sóng alpha thấp đáng kể ở bệnh nhân ở nghiệm pháp tăng thông khí [6], [7].

Tần số là chỉ số quan trọng để phân biệt các sóng trên điện não đồ. Trong nghiên cứu này, kết quả nghiên cứu của chúng tôi cho thấy không có sự khác biệt có ý nghĩa thống kê về tần số của sóng alpha giữa bệnh nhân TTPL với người khỏe mạnh cũng như không có sự khác biệt giữa các vùng vỏ não được ghi ở cả hai giai đoạn nhắm mắt và tăng thông khí.

Như vậy, kết quả nghiên cứu của chúng tôi gợi ý rằng trên bệnh nhân TTPL không có sự biến đổi nào về tần số sóng alpha ở vỏ não cũng như khi thực hiện nghiệm pháp chức năng cơ bản trong điện não đồ như nghiệm pháp tăng thông khí. Như vậy tần số của sóng alpha cũng chỉ là chỉ số để phân biệt được sóng alpha với các sóng khác trên điện não đồ chứ không phải là sự khác biệt về bệnh lý trong TTPL. Kết quả của chúng tôi không tương đồng với nghiên cứu của Howells và CS. (2018) đã chứng minh rằng tần số sóng alpha không thay đổi trên bệnh nhân TTPL [8].

\section{KẾT LUÂ̂N}

Phân tích điện não đồ với sự biến biến đổi năng lượng, biên độ và tần số sóng alpha trên điện não ở bệnh nhẩn TTPL so sánh với ở nhóm chứng khỏe mạnh cho thấy: Năng lượng sóng alpha ở nhóm bệnh thấp hơn có ý nghĩa thống kê so với ở nhóm chứng ở hầu hết các kênh ghi trừ vùng trung tâm hai bên ở cả giai đoạn nhắm mắt và giai đoạn tăng thông khí.

Ở giai đoạn nhắm mắt và tăng thông khí thì biên độ sóng alpha có sự khác biệt có ý nghĩa thống kê về nhóm nghiên cứu và kểnh ghi, trong đó biên độ sóng alpha thấp nhất ở vùng trung tâm và cao nhất ở vùng chẩm hai bên.

Tần số sóng alpha không có sự biến đổi ở bệnh nhân TTPL so với nhóm chứng ở cả hai giai đoạn nhắm mắt và tăng thông khí.

\section{TÀI LIÊU THAM KHẢO}

1. Bùi Quang Huy, Đinh Viêtt Hùng, Phùng Thanh Hải (2016), "Tâm thần phân liệt", Tâm thân phân liệt nguyên nhân, chẩn đoán và điều trị, NXB Y 
học, Hà Nội, 7-118.

2. Bùi Quang Huy, Cao Tiến Đức, Pham Văn Mạnh (2011), "Tâm thần phân liệt", Tầm thần phân liệt, NXB Y học, Hà Nội, 9-85.

3. Moeini M., Khaleghi A., Amiri N., et al. (2014), "Quantitative electroencephalogram (QEEG) spectrum analysis of patients with schizoaffective disorder compared to normal subjects", Iranian Journal of Psychiatry, 9(4): 216221.

4. Kim J.W., Lee Y.S., Han DH., et al. (2015), "Diagnostic utility of quantitative EEG in unmedicated schizophrenia", Neuroscience Letters, 589: 126-131.

5. Itoh T., Sumiyoshi T., Higuchi $Y_{\text {., }}$ et al. (2011), "LORETA analysis of three-dimensional distribution of $\delta$ band activity in schizophrenia: relation to negative symptoms", Neuroscience Research, 70(4): 442-448.

6. Ranlund S., Nottage J., Shaikh M., et al. (2014), "Resting EEG in psychosis and at-risk populations-a possible endophenotype?", Schizophrenia Research, 153(1-3): 96-102.

7. Kirino E. (2004), "Correlation between P300 and EEG rhythm in schizophrenia", Clinical EEG and Neuroscience, 35(3): 137-146.

8. Howells F.M., Temmingh H.S., Hsieh J.H., et al. (2018), "Electroencephalographic delta/alpha frequency activity differentiates psychotic disorders: a study of schizophrenia, bipolar disorder and methamphetamine-induced psychotic disorder", Translational Psychiatry, 8(1): 75.

\title{
HIÊU QUẢ CHƯƠNG TRÌNH CAN THIỆP DICCH VỤ HỖ TRƠ' CHO KHÁ̉CH HÀNG SỬ DUUNG MA TÚY VÀ THÀNH VIÊN GIA ĐİNH HO: NGHIÊN CỨU CAN THIÊPP CộNG ĐÔNG NGẪU NHIÊN Có ĐỐI CHỨNG TẠI PHÚ THỌ, 2015-2017
}

\author{
Lê Mạnh Hùng', Phạm Đức Mạnh ${ }^{1}$, Nguyễn Anh Tuấn ${ }^{2}$,
} Nguyễn Hà Lâm $^{3}$, Nguyễn Hữu Thắng ${ }^{3}$

\section{TÓM TẮT}

Mục tiêu: Đánh giá hiệu quả của chương trình can thiệp trên nhóm cán bộ y tế (CBYT) về các dịch vu y tế đang được cung cẩp cho người sử dụng ma túy và thành viên gia đình họ. Đối tượng và phương pháp: Nghiên cứu can thiêp công đồng ngẫu nhiên có đối chứng thực hiện trên 150 CBYT xã/phường làm công tác phòng, chống HIV/AIDS tại 30 xã/phường tỉnh Phú Thọ. Kết quả: Sau 12 tháng can thiêp tỷ lê CBYT "biết lý do khách hàng sử dung ma túy và gia đình họ không đến theo lịch hẹn" tằng gấp 2 lần; Tỷ lệ CBYTं "tư vấn nhiều cho khách hàng sử dụng ma túy và gia đình họ" tăng 1,7 lần; Tỷ lệ CBYT "thường xuyên khích lệ người sử dụng ma túy và gia đình họ, cảm thấy khách hàng sử dụng ma túy như những khách hàng khác" tăng gấp hơon 1,5 lần. CBYT "biết lý do khách hàng và gia đình họ không đến theo lịch khám và thường xuyên tư vấn cho khác hàng và gia đình ho" có hiệu quả can thiệp cao nhất, đạt trên $60 \%$. Kết luận: Can thiệp giúp cải thiện đáng kể các dich vu đang cung cấp cho người sử dung ma túy tại TYT xã/phường, sự khác biệt có ý nghĩa thống kê về chỉ số hiệu quả ở nhóm can thiệp và đối chứng $(p<0,05)$.

${ }^{1}$ Cuc phòng chống HIV/AIDS, Bô Y tế, Hà Nội

2Viện vệ sinh Dịch tễ Trung Ương, Hà Nội

${ }^{3}$ Trường Đại học Y Hà Nội

Chiu trách nhiệm chính: Lê Manh Hùng

Email: manhhunglevaac@gmail.com

Ngày nhận bài: 24.2.2021

Ngày phản biên khoa học: 29.3.2021

Ngày duyệt bài: 8.4 .2021
Tư khóa: Hiệu quả can thiệp, dịch vụ y tế, cán bộ y tế xã, người sử dụng ma túy, thành viên gia đình.

\section{SUMMARY \\ EVALUATION OF COMMUNITY HEALTH WORKER ABOUT MEDICAL SERVICES FOR DRUG USERS AND THEIR FAMILY MEMBERS: COMMUNITY INTERVENTION STUDY IN PHU THO, 2015-2017}

Objective: To evaluate the effectiveness of the intervention program on community health workers about medical services for drug users and their family members. Subjects and methods: A randomized controlled trial of a community intervention was conducted on 150 health workers in 30 commune health centers (CHCs), Phu Tho from 2015 to 2017. Results: After 12 months, the rate of community health workers knew the reasons for drug users and their families did not come to scheduled appointments increased approximately 2 times; The rate of community health workers gave advice to drug users and their families increased approximately 1.7 times; The rate of community health workers who regularly encourage drug users and their families, and feeling that drug users similar to common customers increased over 1.5 times. 2 fields have the highest effective intervention which was community health workers know why drugs users and their family members did not come to scheduled appointments, and regularly advise clients and their families. They reached over $60 \%$. Conclusions: This intervention program helped to significantly improve medical services at $\mathrm{CHCs}$ which provided drug users. Differences of effective intervention between the 